\title{
Políticas públicas, produções acadêmicas e mestrados profissionais em educação: qual é o lugar ocupado pelos professores?
}

\author{
Public policies, academic productions and professional master's \\ degrees in education: what is the place occupied by teachers?
}

Márcia Regina ONOFRE ${ }^{1}$

Samuel de SOUZA NETO²

\begin{abstract}
Resumo
Esse artigo promove uma discussão sobre o lugar ocupado pelos professores nas esferas políticas e acadêmicas e defende os Mestrados Profissionais em Educaçáo (MPEs) como espaços de ressignificação da profissão. Respaldada em autores do campo da profissionalização do ensino e num estudo exploratório, a pesquisa estrutura-se, a partir da análise documental dos aparatos legais e, posteriormente, do levantamento do tipo estado da arte das produçóes na área. Os dados analisados revelam a permanência do tecnicismo nas políticas de formação e na proposição dos MPEs. Já as produções, anunciam perspectivas inovadoras, na efetivação dos programas, reconhecendo os professores como pesquisadores do campo profissional.
\end{abstract}

Palavras-chave: Mestrados profissionais em educação. Políticas públicas. Produções acadêmicas. Profissionalização do ensino.
Abstract

This article promotes a discussion about the place occupied by teachers in the political and academic spheres and defends the Professional Master's Degrees in Education (MPEs) as spaces where a re-signification of the profession can occur. Supported by authors from the teaching professionalization field and by an exploratory study, the research is structured from the documentary analysis of the legal apparatus and, subsequently, a survey of productions in the area. The data analyzed reveals that technicality remains in the training policies and the proposition of the MPEs. On the other hand, the works in the area announce innovative perspectives in the implementation of the program, recognizing the teachers as researchers of the professional field.

Keywords: Professional master's degree in education. Public policies. Academic productions. Professionalization of teachin.

1 Doutora em Educação pela UNESP-FCL/CAr, Pós-Doutorado em Educação pela UNESP-IBRC - bolsa PNPD (CAPES); Professora Associada do Departamento de Metodologia do Ensino e do Programa de Pós-Graduaçâo Profissional em Educação da Universidade Federal de São Carlos - UFSCar, SP, Brasil. Lattes: http://lattes.cnpq.br/7176529351192598. Orcid: https://orcid.org/0000-0002-5467-185X. E-mail: marciaonofre@ufscar.br

2 Doutor em Educação - FE-USP (SP) - bolsa CAPES, Pós-Doutorado - Centre de recherche interuniversitaire sur la formation et profission enseignante (CRIFPE) - Université de Montréal - bolsa CAPES: Estágio Sênior e bolsa UNESP/PROPG: Estágio Exterior. Professor Associado do Departamento de Educação e do Programa de Pós-Graduação em Educação da Universidade Estadual Paulista (UNESP). Campus Rio Claro com Livre-Docência na UNESP- Rio Claro, SP, Brasil. Pesquisador Internacional CRIFPE/ Montreal. Lattes: http://lattes.cnpq.br/7352600571268275. Orcid: https://orcid.org/0000-0002-89917039. E-mail: samuel.souza-neto@unesp.br 


\section{Desafio inicial: qual é o lugar ocupado pelos professores?}

Iniciamos essa discussão partindo do entendimento de que a formação de professores segue como um grande desafio histórico, político e profissional, principalmente quando focamos no expressivo aumento de pesquisas na área e açôes no campo das políticas públicas implementadas, ocorrido nas três últimas décadas.

No âmbito político, nunca se discutiu e investiu tanto na formação de professores, quanto nas reformas estabelecidas a partir do final do século XX. No entanto, os consideráveis investimentos náo promoveram mudanças expressivas no campo da profissionalização do ensino. Muito pelo contrário. O bojo de ações políticas, articuladas pelo viés da "qualidade do ensino" e do alto capital empregado incidiu sobre os professores por intermédio de cursos aligeirados de formação inicial, cursos de "capacitação" (30h), aquisição de pacotes pedagógicos e materiais didáticos, "bônus" por desempenho profissional e avaliações dos sistemas de ensino como forma de controle e inquirição do capital empregado.

No campo acadêmico, embora as pesquisas tenham avançado, buscando romper com a dicotomia existente entre o conhecimento acadêmico e o conhecimento prático-profissional, os professores da educação básica ainda parecem ocupar a posição de coadjuvantes, sujeitos de pesquisas, colaboradores de estudos e de saberes profissionais, legitimados pela academia.

Esse emaranhado de teias e de discursos incoerentes vem sendo orquestrado sucessivamente, ora pelas políticas educativas autocráticas, que mantém o controle dos sistemas, cerceando a possibilidade da autonomia e da reflexáo docente; ora pelos discursos da academia que se arroga da investigação científica e das bases teóricas da formação dos professores. Nesta perspectiva, o processo de profissionalização do ensino perde a sua essência e legitimidade por não partir da "voz" e do movimento dos professores da escola básica que, historicamente, foram silenciados e acostumados a se colocarem em um papel secundário, em um lugar menor nas discussóes promovidas sobre o seu campo profissional.

Frente a esse paradoxo devemos nos perguntar: Qual é e a quem pertence o conhecimento relevante e pertinente para formar um professor? Por que os professores não participam das decisóes políticas como produtores de um saberfazer? Por que a academia não os reconhece como pesquisadores da própria prática? Afinal, qual é o lugar ocupado pelos professores nas reformas, nas instâncias políticas, acadêmicas e profissionais?

As respostas a essas questóes nos remetem a investigação de estudos e pesquisas na área, tomando por referência a vertente da epistemologia da prática (NÓVOA, 
2019a; HARGREAVES, 2000; TARDIF, 2002; GAUTHIER, 1998) como norteadora de propostas coerentes que afirmem a importância dos professores em assumir essa discussão como profissionais, como protagonistas da própria formação, visando elevar o seu status e sua autoridade como pesquisadores e autores no campo da educação.

Em defesa dessa perspectiva, e partindo da hipótese de que os professores vêm sendo silenciados ao longo da história, não se reconhecendo e nem sendo reconhecidos como profissionais da área, o objetivo desse estudo é promover uma discussão sobre o lugar ocupado pelos professores nas esferas políticas e acadêmicas. Parte-se dos seguintes questionamentos: qual é a concepção de formação subjacente as políticas públicas? Qual é a concepção de formação apresentada nas produçóes acadêmicas?

Buscar a compreensão dessas questôes representa um movimento de denúncia e anúncio frente a justificativa da ausência dos professores nas decisões e a perda de referência de seu ethos profissional, silenciado ao longo da história. Neste sentido, acreditamos que os MPEs podem e devem se configurar como espaços potencializadores de formaçáo e ressignificação da profissáo e oferecer caminhos para o fortalecimento da profissionalizaçáo do ensino.

Com vista a esse processo, desenvolvemos um estudo exploratório-descritivo respaldado em autores do campo da profissionalização do ensino (TARDIF, 2000, 2002, 2013; HARGREAVES, 2000; NÓVOA, 1999; SOUZA NETO; CYRINO; BORGES, 2019; GAUTHIER, 1998; TARDIF; MOSCOSO, 2018; GOODSON, 1992; SHULMAN, 1987), partindo de uma pesquisa documental sobre as políticas públicas no campo da formação dos professores nos últimos trinta anos e de um levantamento bibliográfico de produçóes acadêmicas sobre os MPEs (artigos Scielo, pesquisas na base de dados do Portal CAPES e BDTD) no período de 2010 a 2020. Desse modo, o corpus da análise foi composto por catorze documentos oficiais, quatro artigos, quatro dissertaçóes e uma tese.

Para uma melhor compreensão da discussão, dividimos o artigo em quatro momentos, denominados "movimentos", permitindo a ideia de processo, algo que está em construçáo e que, portanto, abre a possibilidade de novas investigaçóes, questionamentos e reflexóes, convidando todos os atores envolvidos no âmbito da formação docente, a questionarem o lugar ocupado pelos professores nas diferentes esferas discutidas neste ensaio. Por fim, pontuamos como desafio final, a perspectiva dos MPEs como terceiro espaço de formação e de reconhecimento da profissão contribuindo com a revitalizaçáo dos profissionais e com a legitimaçáo do movimento de profissionalização do ensino liderado pelos principais envolvidos nesse processo. 


\section{Primeiro movimento: Qual é o lugar dos professores no processo de profissionalização do ensino?}

A resposta a esse primeiro movimento nos remete a compreensão da historicidade do processo de profissionalização do ensino que tem como marco os anos de 1980 nos Estados Unidos, resultante de todo um cenário constitutivo de evoluçóes ao longo dos séculos (XVI aos dias atuais) (TARDIF, 2013).

Neste sentido, a evolução da educação passa por três longos períodos, denominados por Tardif (2013) de "idades" (idade da vocação, idade do ofício e idade da profissão), marcadas por diversos processos e diferentes concepçóes. A idade do ensino como vocação (século XVI ao século XVIII), marcada pelo início do ensino escolar na Europa e pelas reformas religiosas, concebeu a docência como "profissão de fé", "vocação", uma aprendizagem prática, experienciada pela imitação e pela tentativa-erro, se configurando como um ofício artesanal. Já a idade do ofício (século XVIII ao século XX), foi marcada pela estatização da educação, pelo surgimento das primeiras escolas normais e pela carreira das professoras que passaram a ser assalariadas, rompendo com o caráter vocacional da docência, mas ainda se pautando em uma formação baseada na observação e na imitação da prática. Somente na segunda metade do século XX, com a entrada dos professores na universidade, é que teremos uma nova perspectiva de formação, marcando o ensino como profissão, tendo como propulsor o movimento de profissionalização e uma base de conhecimentos e saberes teórico-profissionais que passou a fundamentar a prática pedagógica dos educadores.

Tal movimento, iniciado na década de 1980, por um grupo de reitores de universidades americanas e fundamentado na "epistemologia da prática” (SOUZA NETO; CYRINO; BORGES, 2019), trazia em seu cerne o reconhecimento e a valorização da ação profissional, e, portanto, dos conhecimentos que se encontram na "base da docência" (SHULMAN, 1987). Dessa forma, a docência como profissão deveria pautar-se em um "ofício feito de saberes" (GAUTHIER,1998), "plurais, heterogêneos e temporais" (TARDIF, 2000) e que respondesse as especificidades da prática de cada professor elevando o status da profissão a uma categoria profissional (NÓVOA, 1999).

De acordo com Hargreaves (2000), o processo de profissionalização passou a estar ancorado a um projeto profissional que deveria ter como alcance os movimentos sociais mais amplos, visando reformas que auxiliassem na aprendizagem profissional desenvolvendo um perfil de professor autônomo, reflexivo, que assumisse a responsabilidade do seu próprio desenvolvimento profissional e o protagonismo na implementação das políticas públicas. Esse 
projeto tinha como proposta a melhora do desempenho do sistema educativo, a passagem de ofício à profissáo e a construção de uma base de conhecimento para o ensino.

No Brasil, o processo de profissionalização do ensino teve sua origem no início da década de 1990, com a publicação dos estudos dos pesquisadores canadenses Tardif, Lessard e Lahaye (1991) e do pesquisador português Antonio Nóvoa (1991) inaugurando um marco teórico-metodológico de análise sobre os percursos pessoais e profissionais de docentes da educação básica, influenciando significativamente a produção intelectual brasileira e tornando-se uma referência nas políticas de formação.

Embora a profissionalização seja um processo em movimento, que deve ser construído pela articulaçáo entre o institucional (normas e valores), o coletivo (grupo profissional) e o individual (professor), as relaçôes de tensão conduzem essas propostas a rumos e perspectivas diferentes.

Segundo a perspectiva da sociologia das profissóes, seria de se esperar que os professores, como categoria profissional, tomassem para si a tarefa de definiçáo e controle dos saberes ligados à sua ação. No entanto, como não há reconhecimento social e legitimidade dos papéis que ocupam e nem valorização dos saberes que mobilizam, esse processo acaba sendo ineficaz (TARDIF, 2002).

A relação dos professores com os seus próprios saberes é inibida pela desvalorização social e por ações políticas que os mantém como tecnocratas do sistema, cumpridores de tarefas e aplicadores de currículo, ou seja, engessando suas açóes e as possibilidades de posicionamento nas diversas esferas profissionais.

Também os saberes relativos à formação profissional dos professores, além de dependerem das políticas e do corpo de especialistas que as elaboram, dependem de correntes e fundamentos teóricos das universidades e de seus pesquisadores. Neste sentido, assim como no campo político, o campo acadêmico também estabelece uma relação de exterioridade com os professores e, de certa forma, uma incoerência epistêmica por ter sido o berço do movimento de profissionalização (SOUZA NETO; CYRINO; BORGES, 2019).

Para que haja uma mudança expressiva desse processo é necessário que a academia reveja o seu papel, pois de nada adianta fazer críticas às políticas educativas que náo valorizam os professores se a própria universidade toma seus lugares nos processos formativos, remetendo-os a uma participação inexpressiva, a um estatuto de práticos, de conservadores e de rotineiros (NÓVOA, 2019a).

O ideário da profissionalização do ensino atribui aos professores o papel de formadores, de produtores de currículo, de protagonistas de sua formaçáo e de sua ação. Nessa perspectiva, o movimento defende a necessidade de "ressignificar o espaço da profissão", em defesa da construção de uma nova profissionalidade docente (NÓVOA, 2019a). 
A necessidade de mudança, reforça a ideia de "colegialidade docente", fortalecida nas escolas, promovendo novos ambientes educativos, novas "comunidades de trabalho" em parceria com as universidades e a sociedade, reforçando os processos de formação e de produção da profissão.

Embora saibamos que as fragilidades e embates históricos no campo da profissionalizaçáo tenham perpassado mais de trinta anos e que ainda estamos caminhando na efetivação desse processo, o avanço de pesquisas e discussóes na área, colocando o professor como produtor de saberes, já contempla uma evolução em seu conceito. Cabe agora à universidade reconhecer a autoridade do docente da educação básica, concebendo a esse profissional um lugar de protagonismo no campo da formação e da pesquisa.

\section{Segundo movimento: Qual é o lugar dos professores nas políticas públicas?}

A compreensão do lugar ocupado pelos professores nas políticas públicas nos remete a necessidade de um breve balanço histórico das reformas educacionais nas três últimas décadas, período de intensificação do movimento de profissionalização do ensino e de mudanças expressivas no campo da formação docente.

A década de 1990 foi marcada por propostas e discursos polarizados sobre o papel do Estado na organizaçáo econômica e a função do poder público nas áreas sociais. Assim, o chamado projeto neoliberal se consolidou, apoiado por pressão de agências internacionais capitalizadoras dos empréstimos financeiros no país, em especial o Banco Mundial (BM) e o Fundo Monetário Internacional (FMI).

Nessa direção, em 1998, a publicação do Relatório Delors (DELORS, 1998) norteou as reformas educacionais nos países subdesenvolvidos e emergentes. O documento propunha o conceito de uma "educação ao longo de toda a vida", que seria alcançado a partir de quatro pilares: "aprender a conhecer"; "aprender a fazer"; "aprender a ser" e "aprender a viver junto".

Nessa perspectiva, para a consecução dos quatro pilares, destacava-se o papel do professor como agente de mudança e como "responsável pela realização do ideário do século XX” (SHIROMA; MORAES; EVANGELISTA, 2002, p. 69). O professor passou a ser visto pelo discurso educacional mundial, como o "redentor", "responsável pela superação das mazelas sociais", desconsiderando a importância da reestruturação de um investimento econômico e social decente no país e enfatizando o ideário de uma escola "salvadora". Esse movimento, fortemente utilizado por uma política apelativa, impactou várias instâncias 
de ensino no país, reverberando nas reformas educacionais, nos cursos de capacitação docente e no contexto das escolas, por meio de ações incoerentes, em defesa da "melhoria da qualidade do ensino" (ONOFRE, 2006).

Em 1996, as propostas derivadas desse projeto dão o tom da nova Lei de Diretrizes e Bases da Educação Nacional (LDBEN) - Lei no 9394/96. Uma lei contraditória em relação à formação de professores, pois ao mesmo tempo que determinava a formação docente em nível superior, inconsequentemente criava os Institutos Superiores de Educação (IES), colocando a carreira docente fora do espectro universitário. O modelo dos Institutos expressava a clara intenção de desresponsabilizar as instituiçóes universitárias pela formação dos professores. Tal modelo apontava para uma "desuniversitarização" da carreira, na medida em que criava modalidades e instituiçóes para desenvolvê-la. Esse processo desastroso resultou em inúmeros prejuízos à formaçáo docente ao privá-la das atividades de pesquisa, pois os Institutos não eram obrigados a desenvolvê-las. Esse modelo de formação tinha como tônica a melhoria dos indicadores educacionais em relação à titulação do quadro docente, sem uma implicação efetiva na melhoria da qualidade de formação e das condiçóes de trabalho futuras dos professores (DOURADO, 2001). Mais uma vez quem pagava a conta eram os professores, "formados a toque de caixa" de forma "aligeirada" e desprofissionalizante.

A partir dos anos 2000, duas propostas foram elaboradas pelo Conselho Nacional de Educação para organização da formação de professores nas instituições de ensino superior: as Diretrizes Curriculares Nacionais para a Formação de Professores da Educação Básica (BRASIL, 2002) e as Diretrizes Curriculares Nacionais para o curso de Pedagogia (BRASIL, 2006). Estas diretrizes serviram de base para a reformulação curricular dos cursos de licenciatura nas universidades brasileiras com ênfase para $o$ desenvolvimento de competências e habilidades a serem desenvolvidas nos futuros professores. A necessidade de reformulação apontado pela política educacional era a de que havia um problema pedagógico, curricular e organizacional nos cursos de formação que se definia pela incapacidade das instituiçôes formadoras no atendimento das demandas. Tais medidas foram insuficientes no sentido de uma discussão democrática e mais abrangente sobre a formação e a valorização do profissional docente e ignoravam a multidimensionalidade das escolas e dos sujeitos nelas presentes. A imposição de uma reorganização curricular e a ausência de uma política de formaçấo de professores decisiva fez com que as medidas propostas não se efetivassem nas universidades.

Buscando reverter esse quadro, em 2007, o Governo federal implantou o Programa de Apoio a Planos de Reestruturação e Expansão das Universidades Federais Brasileiras (REUNI), uma tentativa de expansão dos cursos, redução da evasão e ocupação de vagas ociosas nas instituiçôes. Para isso, foram possibilitadas ofertas de ensino noturno, articulação entre graduação e pós-graduação, ampliação 
de políticas de inclusão e de assistência estudantil. No entanto, as diretrizes foram imprecisas quanto à formação de professores devido a questóes voltadas para: a necessidade do aumento de vagas para cursos noturnos (Diretriz I); a reorganização de cursos de graduação e atualização de metodologias de ensinoaprendizagem (Diretriz III) e articulação da educação superior com a educação básica (Diretriz VI) (BRASIL, 2007).

Ainda em 2007, com a criaçáo da Nova Coordenação de Aperfeiçoamento de Pessoal de Nível Superior (CAPES) (Lei $\left.n^{\circ} 11.502\right)$ e a sua missão em articular a formação inicial e continuada de professores da educação básica, foram traçados novos rumos para a profissionalização do ensino em nosso país. Esse panorama representava um avanço histórico para o campo da formação no Brasil, "um caso único no mundo" (NÓVOA, 2019b), de uma entidade de pós-graduação e pesquisa tomar para si a responsabilidade por esse tipo de açáo articuladora e processual.

O resultado dessa mudança foi evidenciado em 2009 com a instituição de uma Política Nacional para a Formaçáo de Profissionais do Magistério da Educação Básica, possibilitando a criação de vários programas e promovendo parcerias entre as instituiçóes de educação superior e os sistemas de educação básica (BRASIL, 2009). Dentre esses programas destaca-se: Programa de Consolidação das Licenciaturas (Prodocência), Programa Institucional de Bolsas de Iniciação à Docência (PIBID), Observatório da Educação e o Plano Nacional de Formação de Professores da Educação Básica (PARFOR).

Entre 2010 e 2014, também foram criados dois grandes e importantes planos norteadores das açôes de formação no país, principalmente para a formação continuada de professores: o Plano Nacional de Pós-Graduação (PNPG) (20112020) e o Plano Nacional de Educação (PNE) (2014-2024). Tais propostas se configuravam como desafios de ordem político-pedagógica, alinhavados em suas perspectivas de intencionalidade e ação. O Plano Nacional de Educação (PNE), composto por vinte metas a serem atingidas em dez anos na educação brasileira, destacava que a formação em nível superior seria a condição fundamental para que o professor assumisse a docência em todas as etapas e modalidades da educação.

Assim sendo, a CAPES assumiu o compromisso de promover encaminhamentos e propostas de "inovaçóes" das políticas de formação dos professores, sendo uma delas a criação de Fóruns Estaduais Permanentes de Apoio à Formação Docente, com representantes de várias instituiçóes, sendo presididos pelos secretários estaduais de educação.

Em 2015, foram elaboradas as Diretrizes Curriculares Nacionais para a Formaçáo Inicial e Continuada em Nível Superior de Profissionais do Magistério para a Educação Básica, um avanço significativo, em substituição as Diretrizes de 2002. Essas normativas passaram a reorganizar os cursos de licenciatura com o compromisso da formação de profissionais para o exercício da docência na 
educação básica e em todas as modalidades de educação: Educação de Jovens e Adultos, Educação Especial, Educação Profissional e Tecnológica, Educaçáo do Campo, Educação Escolar Indígena, Educação a Distância e Educação Escolar Quilombola (BRASIL, 2015). Pela primeira vez na história, as reformas políticas começavam a reconhecer a importância dos professores da educação básica na tomada de decisôes e a legitimar, mesmo que de forma tímida, o seu posicionamento em diferentes instâncias educativas.

As Diretrizes de 2015 deram um salto em relação a concepção de formação de professores, propondo-a como um processo contínuo, articulando formação inicial e continuada, bem como a diversidade de questóes voltadas para os reclamos acadêmicos e sociais que vinham de longa data. A política parecia querer "acertar a mão" em um processo de construção coletiva e dialógica que caminhava no sentido da equidade e da valorização da categoria docente. Infelizmente, em 2019, todo esse movimento foi interrompido com a aprovação da Resolução $n^{\circ} 2$ (BRASIL, 2019) que se configurava como uma nova proposta no campo da formação, mas que na verdade selava, novamente, um retrocesso histórico e rançoso no campo educativo, negando todo o processo que vinha sendo construído.

Os documentos disparadores desse processo de elaboração das Diretrizes de 2019 foram publicados em 2018, num panorama de críticas e crises na economia, somada à reestruturação desastrosa do ensino médio, com a publicação da Base Nacional Curricular Comum (BNCC) (BRASIL, 2018) e da Base Nacional Comum para a Formação de Professores (BNCFP) (BRASIL, 2018). Esses documentos instituíam um conjunto de competências e habilidades (procedimentos e práticas) que reforçavam uma formação acrítica e tecnicista de reprodução de métodos, atribuindo ao professor, novamente, a figura de tecnocrata do sistema.

Ao longo desses trinta anos de história, embora o movimento de profissionalização do ensino tenha avançado em alguns pontos, o impacto das propostas não foi suficiente e nem expressivo devido às políticas partidárias respaldadas numa visão economicista, autocrata e retrógrada de educação no país.

$\mathrm{O}$ quadro que assistimos atualmente, de retrocessos e incoerências, apenas reforça o que historicamente vivenciamos ao longo das décadas: a ausência dos professores nas políticas públicas, a inexistência da contribuição deles nas reformas e a falta de reconhecimento de sua importância social.

Os professores, ora vistos como "algozes incompetentes", ora como "redentores e responsáveis pela superação das mazelas sociais”, não se reconhecem como profissionais da área, como pesquisadores e produtores de saberes, como formuladores de currículos e programas, como especialistas responsáveis pela implantação de açóes efetivas nas escolas. Neste sentido, podemos afirmar que não há lugar para os professores da educação básica nas políticas públicas, pois o 
sistema proletariza, fragiliza e controla o seu fazer e, portanto, silencia o seu saber num movimento contínuo de desprofissionalização.

Devido a esse quadro, consideramos que o recorte do estudo voltado para a compreensão dos programas de Mestrado Profissional em Educação apresenta relevância, no que tange a investigação das "vozes" dos professores da educação básica em outros espaços formativos, na tentativa de promover mudanças de postura e mentalidade em relação ao seu papel profissional e importância social, tornando-os pesquisadores da sua própria prática.

\section{Terceiro Movimento: Qual é o lugar dos professores nos Mestrados Profissionais em Educação?}

O processo de implantação dos Mestrados Profissionais (MPs) no Brasil teve como marco histórico o ano de 2017, com a regulamentação de seu funcionamento pelas Portarias MEC n 389 e pela Portaria CAPES n ${ }^{\circ} 131$, e o ano de 1998, que reconheceu os Programas com a Portaria da CAPES de no 80/1998 (NEVES, 1998).

Como uma modalidade de pós-graduação stricto sensu, o Mestrado Profissional traz em seu cerne a concepção de "capacitação de profissionais" em diversas áreas do conhecimento, mediante estudos de técnicas e processos ou temáticas que atendam a demanda do mercado de trabalho, como uma alternativa para a formação de professores-pesquisadores, através de uma configuração de ensino direcionada para a prática, buscando a aproximação da produção acadêmica com o mundo do trabalho (BRASIL, 2014).

Nessa modalidade de mestrado, há o incentivo à elaboração de "produtos educacionais", efetivados ao final do curso, vinculados a problemas reais da área de atuaçáo do mestrando-pesquisador e, de acordo com a natureza da área e a finalidade do curso, podendo ser apresentados em diversos formatos. Tais especificidades exigem que o acompanhamento e a avaliação sejam feitos com base em critérios diferenciados, definidos pelas áreas de avaliação, e realizados por subcomissão específica, mesmo se realizados concomitantemente aos programas acadêmicos (BRASIL, 2002).

$\mathrm{Na}$ área da educação, os primeiros Mestrados Profissionais foram ofertados em 2009 pela Universidade Federal de Juiz de Fora (UFJF) e em 2011, pela Universidade do estado da Bahia (UNEB).

Embora a institucionalização da pós-graduação profissional no Brasil ainda seja recente, náo podemos negar o expressivo aumento de cursos ao longo desses dez anos. Atualmente, o Brasil possui quarenta e quatro Mestrados Profissionais na área da Educação, distribuídos nas cinco regiốes do país: vinte na regiấo 
Sudeste (doze em São Paulo; sete em Minas Gerais e um no Rio de Janeiro); onze na região Nordeste (seis na Bahia; três em Pernambuco; dois na Paraíba); oito na região Sul (cinco no Rio Grande do Sul, dois no Paraná e um em Santa Catarina); dois na regiáo Centro-Oeste (dois no Mato Grosso do Sul e um no Distrito Federal) e dois na região Norte (um em Roraima e um no Tocantins) (BRASIL, 2020).

No âmbito das associaçóes científicas e fóruns, os ganhos também foram consideráveis com a união da Associaçáo Nacional de Pós-Graduação e Pesquisa em Educação (ANPED) e Fórum de Pró-Reitores de Pós-Graduação e Pesquisa em Educação (FORPRED) ao Fórum Nacional dos Mestrados Profissionais (FORPROF), criado em 2006, e o Fórum Nacional dos Mestrados Profissionais em Educação (FOMPE), em 2014 (FIALHO; HETKOWSKI, 2017).

A inserção dessas associações e fóruns tem possibilitado um rearranjo dos MPEs que, diferentemente dos MPs, tem concebido um processo formativo inovador e articulado com questóes mais amplas, mudando a concepçáo de aplicação para a de investigação; de capacitação para reflexão sobre a prática; do produto final para a elaboração de dissertaçóes, elevando a qualificação dos programas, a produção das pesquisas e, consequentemente a formação do professor-pesquisador.

Essas constataçóes foram identificadas em uma pesquisa do tipo estado da arte (ROMANOWSKI; ENS, 2006) realizada no início de 2020, sobre as produçôes acadêmicas na área em artigos da Scientific Eletronic Library Online (Scielo), base de dados do Portal CAPES e Biblioteca Digital Brasileira de Teses e Dissertaçóes (BDTD) do Instituto Brasileiro de Informação em Ciência e Tecnologia (IBICT) com recorte para os Mestrados Profissionais em Educação.

$\mathrm{O}$ estudo se estruturou em duas fases de levantamento: A primeira com a busca nos artigos da Scielo e a segunda, no Catálogo de Teses \& Dissertaçóes CAPES e na BDTD - IBICT.

A primeira fase foi realizada no primeiro trimestre de 2020, com a busca nos artigos da Scielo. O recorte temporal foi de 2010 a 2020, devido à implantação dos programas a partir de 2009. As palavras-chave utilizadas foram "Mestrado Profissional em Educação" e "Profissionalização docente". A primeira seleção remeteu a trinta e um artigos, sendo cinco artigos de interesse. A segunda seleção foi realizada com as palavras-chave "Mestrados Profissionais em Educaçáo" e "Profissionalização docente", que remeteu a vinte e sete artigos. À terceira busca, foi adicionada a palavra-chave "Desenvolvimento profissional docente", remetendo a vinte e dois artigos. A partir do levantamento, foram eliminados os resultados duplicados, os artigos que se referiram aos Mestrados Profissionais de áreas de ensino específicas (Matemática, Ciências Biológicas, Física), e os trabalhos que se distanciavam da temática em questáo. Ao todo, foram selecionados quatro artigos para análise (ANDRÉ; PRINCEPE, 2017; CUNHA; AGRANIONIH, 2017; 
CAMPOS; GUÉRIOS, 2017; AMBROSETTI; CALIL, 2016).

Dos cinco artigos selecionados, três artigos (2017) faziam parte da mesma edição do Dossiê - "Mestrado Profissional e formação de professores: experiências, desafios e perspectivas para a Educação Básica" - publicado no Periódico Educar em Revista (Qualis CAPES A1) da Universidade Federal do Paraná. Um artigo (2016) foi publicado no Periódico Reflexão e Ação (Qualis CAPES B1) do Programa de Pós-Graduação em Educação da Universidade de Santa Cruz do Sul (UNISC).

As análises dos artigos revelaram pontos interessantes e fundamentais para o entendimento do lugar ocupado pelos professores nesses Programas e as concepçóes subjacentes nesse processo. O artigo de André e Principe (2017), por exemplo, tomou por referência de análise as dissertaçóes defendidas no Mestrado Profissional em Educação da Pontifícia Universidade Católica (PUC-SP) e concluiu que os trabalhos traduziam a dimensão reflexiva e a articulação entre investigação e prática pedagógica, atingindo assim os objetivos do programa.

Já o trabalho de Cunha e Agranionih (2017), que analisou as dissertaçóes produzidas pela primeira turma do Mestrado em Educação da Universidade Federal de Paraná (UFPR), destacou a contribuição das mesmas para a profissionalidade dos professores, a ampliação dos horizontes teóricos, a reflexáo de seus contextos de trabalho e a intervenção em suas realidades por meio da pesquisa.

Os dois artigos discutidos parecem revelar as potencialidades das pesquisas elaboradas pelos professores. Também representam um avanço significativo frente as proposiçóes apresentadas no documento legal sobre o "domínio de metodologias e aplicação orientada para o campo profissional”.

Já o estudo de Ambrosetti e Calil (2016), sobre os resultados de uma pesquisa em relação a perspectiva dos participantes de um Mestrado Profissional em Educação da Universidade de Taubaté (UNITAU), apontou as contribuiçóes do curso para o desenvolvimento e atuação profissional dos participantes, indicando que os estudos teóricos articulados à análise das práticas, bem como a apropriação de procedimentos da pesquisa científica, permitiu aos professores um novo olhar sobre o contexto de trabalho e da profissão, se configurando em uma experiência transformadora das concepçōes e práticas desses profissionais.

Por fim, o estudo de Campos e Guérios (2017), sobre o processo de estruturação e implementação de um Programa de Pós-Graduação na área da Educação na Universidade Federal de Paraná (UFPR), nos alerta para a importância de aprofundamentos de estudos e pesquisas sobre essa nova modalidade de formação, buscando pistas para essa experiência que está em fase inicial.

Corroboramos com essa constatação, devido à ausência comprovada de estudos na área em detrimento, ao montante de pesquisas sobre os Mestrados profissionais em Ensino e que, portanto, justifica a pertinência e relevância dos dados aqui apresentados. 
A segunda fase foi realizada no segundo trimestre de 2020, com a busca no Catálogo de Teses \& Dissertaçóes - CAPES e na BDTD - IBICT. O recorte temporal também foi de 2010 a 2020. As palavras-chave utilizadas foram "Mestrado Profissional em Educação" e "Profissionalização docente". A primeira seleção no Catálogo de Teses \& Dissertaçóes - CAPES remeteu para noventa e seis pesquisas sendo cinco trabalhos de interesse. A segunda seleção foi na BDTD - IBICT que remeteu para trinta e uma pesquisas sendo duas de interesse. A partir do levantamento, foram eliminados, novamente, os resultados duplicados, as pesquisas que se que se referiram aos Mestrados Profissionais de áreas de ensino específicas e os estudos que se distanciavam da temática em questão. Ao todo foram selecionados quatro artigos para análise (NASCIMENTO, 2019; ROCHA, 2018; PACITT, 2017; TAVARES, 2017). Das pesquisas selecionadas, três eram dissertações de Mestrado (ROCHA, 2018; PACITT, 2017; TAVARES, 2017) e uma tese de Doutorado (NASCIMENTO, 2019).

A tese de Nascimento (2019), buscou a compreensão teórico-metodológica da inserção dos MPEs, visando conhecer a orientação das propostas desses cursos através da análise dos documentos que os normatizavam (PNE, PNPG) e das políticas legais que os regulamentavam (CAPES, MEC). Os resultados da pesquisa apontaram que as produçóes finais organizadas, majoritariamente, através das dissertações, contradiziam o discurso observado nos documentos legais, seguindo um modelo acadêmico, justamente na tentativa de garantir um padrão de qualidade. Tais consideraçóes convergem para os apontamentos do artigo de André e Princepe (2017).

A pesquisa de Rocha (2018), analisou um programa de mestrado profissional em educação no interior paulista, buscando compreender a voz dos egressos e as relaçóes estabelecidas entre a formaçáo e o desenvolvimento profissional. Os resultados apontaram que o curso analisado se configurou como uma formação propulsora de mudanças no desenvolvimento profissional daqueles que o fizeram, exercendo influências significativas em suas práticas educativas, no desenvolvimento da concepçáo de profissionalidade, da autonomia moral e da responsabilidade social. Tal contatação também reforça os resultados apontados, anteriormente, por Ambrosetti e Calil (2016).

A dissertação de Pacitt (2017), investigou as contribuições do Mestrado Profissional em Educação: Formação de Formadores (Formep) para o desenvolvimento profissional dos coordenadores pedagógicos da Rede Municipal de Ensino da cidade de São Paulo. Os resultados indicam a contribuição do MPE para o desenvolvimento profissional dos coordenadores pedagógicos, proporcionado pela investigaçáo, escuta ativa e análise da prática profissional, permitindo um olhar mais crítico e reflexivo do contexto de trabalho e, portanto, um novo significado e valorização desses profissionais. 
O estudo de Tavares (2017), buscou contextualizar em que moldes esta modalidade de pós-graduação vem se configurando e o que ela pode indicar em função de seus objetivos. Os resultados apontaram que a inserção dos MPs na Educação ressignificou os termos inovação e profissionalização e criou um paradigma na pós-graduação brasileira, voltado para a prática profissional.

Um balanço dos artigos e pesquisas aqui analisados, sobre os Mestrados Profissionais em Educação, anunciam algumas perspectivas para o fortalecimento da base epistêmica no campo da pesquisa e da formação, ao contemplar relaçóes entre ensino superior e educação básica; profissionalidade e autonomia docente; articulação entre investigação e prática profissional; aprofundamento teórico, reflexão e intervenção no campo profissional; reconhecimento e valorização docente, contribuindo para o processo de profissionalização docente.

Neste sentido, podemos afirmar que os Mestrados Profissionais em Educação parecem estar se configurando como espaços potencializadores do desenvolvimento profissional docente, colocando o professor no centro do processo formativo, como produtor de conhecimento, pesquisador da própria prática e profissional reflexivo, fortalecendo a coletividade, a profissionalidade e a autonomia docente. No entanto, esse processo só está sendo possível devido à contribuição dos programas que vem se debruçando na estruturação de um curso de qualidade com a mesma formatação do mestrado acadêmico, possibilitando aos docentes da educação básica o aprofundamento teóricoprático, a participação em grupos de pesquisa, a elaboraçáo de artigos e a realização de dissertaçóes que os qualificam como pesquisadores.

\section{Desafio Final: \\ Um terceiro espaço de formação e atuação para os professores}

Os dados apresentados nesta análise, configurados em três movimentos fundamentais para a compreensão do processo histórico-político-pedagógico de profissionalização docente, possibilitaram respostas para os dois questionamentos iniciais e para a compreensão do lugar ocupado pelos professores em diferentes instâncias de formação.

A análise realizada nos documentos oficiais, revelou um quadro desolador e permanente de proposições tecnicistas, reprodutivistas e pragmáticas baseadas num conjunto de competências e habilidades que reforçam uma formação acrítica e desqualificante, atribuindo ao professor a figura de tecnocrata do sistema. Em relação aos MPEs, as proposições não são diferentes, pois defendem a "capacitação de profissionais", a elaboração de um "produto final" mediante estudos de "técnicas e processos" e a "aplicação orientada" para o campo 
profissional. Portanto, no campo político, compreendemos que o lugar ocupado pelos professores da educaçáo básica, continua a ser o de meros executores dos projetos educacionais, em uma relação de desrespeito e desqualificação de sua capacidade crítica como profissional e pesquisador, colaborando com o processo crescente de desprofissionalização do ensino.

Já as produçóes acadêmicas analisadas, anunciam perspectivas inovadoras para o fortalecimento da base epistêmica no campo da pesquisa e da formaçáo, ao contemplar, na perspectiva dos programas de MPE, a valorizaçáo do professor pesquisador e protagonista de sua formação e ação.

Neste sentido, colocamos como desafio final convidar a todos os profissionais da educação, juntamente com Zeichner (2010), a construirmos um "terceiro espaço" no campo de formaçáo de professores, reconhecendo os MPEs como potencializadores desse processo, promovendo a aproximação entre a universidade e a escola, possibilitando um diálogo mútuo entre os conhecimentos práticoprofissionais e os conhecimentos acadêmicos, fortalecendo a presença da universidade na escola e da escola na universidade e, possibilitando aos professores da educação básica, o protagonismo silenciado em todos esses anos.

\section{Referências}

AMbrosetTI, N. B.; CALIL, A. M. G. C. Contribuiçôes do Mestrado Profissional em Educação para a formação docente. Revista Reflexáo e Açáo, Santa Cruz do Sul, RS, v. 24, n. 3, p.85-104, set./dez. 2016. DOI: http:// dx.doi.org/10.17058/rea.v24i3.7526. Disponível em: https://online.unisc.br/ seer/index.php/reflex/article/view/7526. Acesso em: 03 set. 2020.

ANDRÉ, M.; PRINCEPE, L. O lugar da pesquisa no Mestrado Profissional em Educação. Educação em revista, Curitiba, n. 63, p. 103-117, jan./mar. 2017. DOI: 10.1590/0104-4060.49805. Disponível em: https://repositorio.usp.br/ item/002915142. Acesso em: 02 set. 2020.

BRASIL. Conselho Nacional de Educação. Parecer CNE/CP no 2/2015, de 09 de junho de 2015. Brasília: MEC, 2015. Disponível em: http://portal.mec. gov.br/programa-mais-educacao/30000-uncategorised/21123-2015-pareceresdo-conselho-pleno. Acesso em: 02 set. 2020.

BRASIL. Conselho Nacional de Educação. Resoluçáo CNE/CES no 24, de 18 de dezembro de 2002. Altera a redação do parágrafo $4^{\circ}$ do artigo $1^{\circ}$ e o artigo $2^{\circ}$, da Resolução CNE/CES 1/2001, que estabelece normas para o funcionamento de cursos de pós-graduação. Brasília: MEC, 2002. Disponível em: http://portal.mec.gov. $\mathrm{br} /$ index.php?option=com_docman\&view=download\&alias=78331-rces024-02pdf\&category_slug=dezembro-2017-pdf\&Itemid=30192. Acesso em: 02 set. 2020. 
BRASIL. Conselho Nacional de Educação. Resolução CNE/CP no 1, de 15 de maio de 2006. Institui Diretrizes Curriculares Nacionais para o Curso de Graduação em Pedagogia, licenciatura. Brasília: MEC, 2006. Disponível em: http://portal.mec. gov.br/cne/arquivos/pdf/rcp01_06.pdf. Acesso em: 02 set. 2020.

BRASIL. Ministério da Educação. Base Nacional Comum Curricular. Brasília: MEC, 2017.

BRASIL. Ministério da Educação. Lei no 13.005, de 25 de junho de 2014. Aprova o Plano Nacional de Educação - PNE e dá outras providências. [Brasília, DF: Presidência da República, 2014.] Disponível em: http://www.planalto.gov.br/ ccivil_03/_ato2011-2014/2014/lei/l13005.htm. Acesso em: 08 set. 2020.

BRASIL. Ministério da Educação. Parecer, no 977, de 03 de dezembro de 1965. [Brasília: MEC, 1965]. Disponível em: https://www.capes.gov.br/images/stories/ download/legislacao/Parecer_CESU_977_1965.pdf. Acesso em: 01 set. 2020.

BRASIL. Ministério da Educação. Plano nacional de pós-graduaçáo: PNPG 2011-2020. [Brasília: CAPES, 2010.

BRASIL. Ministério da Educação. Reuni: reestruturação e expansão das Universidades Federais (diretrizes gerais). Brasília: MEC, 2007.

BRASIL. Ministério da Educação. Conselho Nacional de Educação. Parecer CNE/ CP 9/2001: homologado. Brasília: MEC, 2002.

BRASIL. Ministério da Educação. Conselho Nacional de Educação. Resoluçáo $\mathrm{CNE} / \mathrm{CP} \mathrm{n}^{\circ}$ 2, de 20 de dezembro de 2019. Define as Diretrizes Curriculares Nacionais para a Formação Inicial de Professores para a Educação Básica e institui a Base Nacional Comum para a Formação Inicial de Professores da Educação Básica (BNC-Formaçấo). [Brasília: MEC, 2019.]. Disponível em: http://portal.mec.gov. br/docman/dezembro-2019-pdf/135951-rcp002-19/file. Acesso em: 04 set. 2020.

BRASIL. Ministério da Educação. Coordenação de Aperfeiçoamento de Pessoal de Nível Superior. Plataforma Sucupira. Disponível em: https://sucupira.capes.gov. br/sucupira/. Acesso em: 02 set. 2020.

BRASIL. Ministério da Educação. Coordenação de Aperfeiçoamento de Pessoal de Nível Superior. Portaria normativa no 389, de 23 de março de 2017. Dispóe sobre o mestrado e doutorado profissional no âmbito da pós-graduação stricto sensu. [Brasília: MEC, 2019.]

BRASIL. Ministério da Educação. Diretoria da Formação e Desenvolvimento dos Profissionais da Educação Básica. Proposta para a Base Nacional Comum da Formaçáo de Professores. Brasília: MEC, 2018. 
BRASIL. Presidência da República. Decreto no 6.755, de 29 de janeiro de 2009. Institui a Política Nacional de Formação de Profissionais do Magistério da Educação Básica, disciplina a atuação da Coordenação de Aperfeiçoamento de Pessoal de Nível Superior - CAPES no fomento a programas de formação inicial e continuada, e dá outras providências. [Brasília: Presidência da República, 2009]. Disponível em: http:// www.planalto.gov.br/ccivil_03/_ato2007-2010/2009/decreto/D6755impressao. htm. Acesso em: 10 set. 2020.

BRASIL. Presidência da República. Lei no 11.502, de 11 de julho de 2007. Modifica as competências e a estrutura organizacional da fundação Coordenação de Aperfeiçoamento de Pessoal de Nível Superior - CAPES, de que trata a Lei no 8.405, de 9 de janeiro de 1992; e altera as Leis nos 8.405, de 9 de janeiro de 1992, e 11.273, de 6 de fevereiro de 2006, que autoriza a concessáo de bolsas de estudo e de pesquisa a participantes de programas de formação inicial e continuada de professores para a educaçáo básica. [Brasília: Presidência da República, 2007]. Disponível em: http://www.planalto.gov.br/ccivil_03/_ato2007-2010/2007/lei/ 111502.htm. Acesso em: 10 set. 2020.

CAMPOS, M. A. T.; GUERIOS, E. Mestrado Profissional em Educação: reflexões acerca de uma experiência de formação à luz da autonomia e da profissionalidade docente. Educar em revista, Curitiba, n. 63, p. 35-51, jan./mar. 2017.

CUNHA, C. M.; AGRANIONIH, N. T. Mestrado Profissional em Educação: Teoria e Prática de Ensino - qualificação dos processos de educar na pesquisa da Educação Básica. Educar em revista, Curitiba, n.63, pp.119-135. ISSN 1984-0411.

DELORS, J. (org.) Educação: um tesouro a descobrir. Brasília: MEC: UNESCO; São Paulo: Cortez, 1998.

DOURADO, L. F. A reforma do Estado e as políticas de formação de professores nos anos de 1990. In: DOURADO, L. F; PARO, V. H. (org.) Políticas Públicas e educação básica. São Paulo: Xamã, 2001.

FIALHO, N. H.; HETKOWSKI, T. M. Mestrados Profissionais em Educação: novas perspectivas da pós-graduaçáo no cenário brasileiro. Educar em Revista, Curitiba, n. 63, p. 19-34, jan./mar. 2017. DOI: http://dx.doi.org/10.1590/01044060.49135. Disponível em: https://revistas.ufpr.br/educar/article/view/49135. Acesso em: 07 set. 2020.

GAUTHIER, C. Por uma teoria da Pedagogia: pesquisas contemporâneas sobre o saber docente. Ijuí: Unijuí, 1998.

GIL, A. C. Métodos e técnicas de Pesquisa Social. 6. ed. São Paulo: Atlas, 2008. 
GOODSON, I. F. Dar voz ao professor: as histórias de vida dos professores e o seu desenvolvimento profissional. In: NÓVOA, A. (org.). Vidas de professores. 2. ed. Porto: Porto Editora, 1992. p. 63-78.

HARGREAVES, A. Four Ages of Professionalism and Professional Learning. Teachers and Teaching, London, v. 6, issue 2, 2000, p.151-182. DOI: https:// doi.org/10.1080/713698714. Disponível em: https://www.tandfonline.com/doi/ abs/10.1080/713698714. Acesso em: 08 set. 2020.

NASCIMENTO, L. S. Os Mestrados Profissionais em Educaçáo. 2019. Tese (Doutorado) -- Universidade Federal do Rio de Janeiro, 2019. Disponível em: https://ppge.educacao.ufrj.br/teses2019/tLUCIANE\%20DA\%20SILVA\%20 NASCIMENTO.pdf. Acesso em: 08 set. 2020.

NEVES, A. A. B. Portaria no 80, de 16 de dezembro de 1998. Revista Brasileira de Pós-Graduaçáo, v. 2, n. 4, 11. DOI: https://doi.org/10.21713/23582332.2005.v2.88. Disponível em: http://ojs.rbpg.capes.gov.br/index.php/rbpg/ article/view/88. Acesso em: 02 set. 2020.

NÓVOA, A. (Org.). Vidas de professores. Porto: Porto Editora, 1992.

NÓVOA, A. Entre a formação e a profissão: ensaio sobre o modo como nos tornamos professores. Currículo sem Fronteiras, [S.l.], v. 19, n. 1, p. 198208, jan./abr. 2019b. Disponível em: http://www.curriculosemfronteiras.org/ vol19iss1articles/novoa.pdf. Acesso em: 03 set. 2020.

NÓVOA, A. Os professores e a sua formação num tempo de metamorfose da escola. Educaçáo \& Realidade, Porto Alegre, v. 44, n. 3, e84910, 2019a. DOI: http://dx.doi.org/10.1590/2175-623684910. Disponível em: https://www.scielo. br/scielo.php?script=sci_arttext\&pid=S2175-62362019000300402. Acesso em: 02 set. 2020.

NÓVOA, A. Os professores na virada do milênio: do excesso dos discursos à pobreza das práticas. Educaçáa e Pesquisa, São Paulo, v. 25, n. 1, p. 11-20, jan./jun. 1999. Disponível em: https://www.scielo.br/scielo.php?pid=S151797021999000100002\&script=sci_abstract\&tlng=pt. Acesso em: 01 set. 2020.

NÓVOA, A. Para o estudo sócio-histórico da gênese e desenvolvimento da profissão docente. Revista Teoria e Educaçáo, Porto Alegre, v. 4, p.91-108, 1991.

ONOFRE, M. R. A experiência de pesquisa na formaçáo básica e seu impacto na atuaçáo docente na visão de profissionais do Ensino Fundamental I. 2006. Tese (Doutorado em Educação) -- Universidade Estadual Paulista, Araraquara, 2006. 
PACITTI, M. F. Mestrado Profissional em Educaçáo - Formaçáo de Formadores (PUC-SP): contribuições para coordenadores pedagógicos da Rede Municipal de Ensino de São Paulo. 2017. Dissertação (Mestrado em Educação) -- Pontifícia Universidade Católica de São Paulo, São Paulo, 2017. Disponível em: https://bdtd.ibict.br/vufind/Record/PUC_SP-1_408974f8d49 6f8a950c3c2080c4a6412. Acesso em: 01 set. 2020.

\section{ROCHA, A. C. S. As influências do MPE no desenvolvimento profissional} de seus egressos. 2018. Dissertação (Mestrado em Educação) -- Programa de Pós-Graduação em Educação, Universidade de Taubaté, São Paulo, 2018. Disponível em: https://mpemdh.unitau.br/wp-content/uploads/2016/ dissertacoes/mpe/a/Ana-Carolina-da-Silva-Rocha.pdf. Acesso em: 08 set. 2020.

ROMANOWSKI, J. P.; ENS, R. T. As pesquisas denominadas do tipo "Estado da Arte”. Diálogos Educacionais, Curitiba, v. 6, n.19, p.37-50, set./dez. 2006. Disponível em: https://periodicos.pucpr.br/index.php/dialogoeducacional/ article/view/24176. Acesso em: 09 set. 2020.

SELLTIZ, C.; JAHODA, M.; DEUTSCH, M.; COOK, S. M. Métodos de pesquisa das relaçóes sociais. São Paulo: Herder: EDUSP, 1965.

SHIROMA, E. O.; MORAES, M.C. M.; EVANGELISTA, O. Política Educacional. Rio de Janeiro: DP\&A, 2002.

SHULMAN,L. Knowledgeand teaching: foundations of thenew reform.Harvard Educational Review, Cambridge, MASS, v. 57, issue 1, p.4-14, apr. 1987. DOI: https://doi.org/10.17763/haer.57.1.j463w79r56455411. Disponível em: https://hepgjournals.org/doi/10.17763/haer.57.1.j463w79r56455411. Acesso em: 01 set. 2020 .

SOUZA NETO. S. CYRINO; M.; BORGES, C. O Estágio Curricular Supervisionado como Lócus Central da Profissionalização do Ensino. Revista Portuguesa de Educação, 32(1), pp. 52-72. doi: 10.21814/rpe.13439.

TARDIF, M. A profissionalização do ensino passados trinta anos: dois passos para a frente, três para trás. Educaçáo e Sociedade, Campinas, v. 34, n. 123, abr./ jun., 2013. DOI: https://doi.org/10.1590/S0101-73302013000200013. Disponível em: https://www.scielo.br/scielo.php?pid=S010173302013000200013\&script=sci_abstract\&tlng=pt. Acesso em: 02 set. 2020.

TARDIF, M. Saberes docentes e formaçáo profissional. Petrópolis: Vozes, 2002. 
TARDIF, M. Saberes profissionais dos professores e conhecimentos universitários: elementos para uma epistemologia da prática profissional dos professores e suas consequências em relação à formação para o magistério. Revista Brasileira de Educaçáo, Rio de Janeiro, n. 13, p.5-24, jan./fev./mar./abr. 2000. Disponível em: http://anped.tempsite.ws/novo_portal/rbe/rbedigital/RBDE13/RBDE13_05_ MAURICE_TARDIF.pdf. Acesso em: 10 set. 2020.

TARDIF, M.; MOSCOSO, J. T. A noção de "profissional reflexivo" na educação: atualidade, usos e limites. Cadernos de Pesquisa, São Paulo, v.48, n.168, p.388-411, abr./jun. 2018. DOI: https://doi.org/10.1590/198053145271. Disponível em: https://www.scielo.br/scielo.php?script=sci_arttext\&pid=S010015742018000200388\&lng=es\&tlng=es. Acesso em: 09 set. 2020.

TARDIF, M.; LESSARD, C.; LAHAYE, L. Os professores diante do saber: esboço de uma problemática do saber docente. Revista Teoria e Educaçáo, Porto Alegre, v. 4, p. 31-55, 1991.

TAVARES, P. D.V. B. Mestrado Profissional em Educaçáo: histórico e tendências. 2017. Dissertação (Mestrado), Programa de Pós-Graduação em Educação, Universidade Federal de Viçosa, Viçosa, MG, 2017. Disponível em: https://www.locus.ufv.br/handle/123456789/24323. Acesso em: 08 set. 2020.

ZEICHNER, K. Repensando as conexóes entre a formação na universidade e as experiências de campo na formação de professores em faculdades e universidade. Educaçáo, Santa Maria, RS, v. 35, n. 3, p. 479-504, set./dez. 2010. DOI: https:// doi.org/10.5902/198464442357. Disponível em: https://periodicos.ufsm.br/ reveducacao/article/view/2357. Acesso em: 05 set. 2020. 